\title{
VaRiabilidade Genética e Sensibilidade de Acessos de Pistia stratiotes AO HERBICIDA GLYPHOSATE ${ }^{1}$
}

\author{
Genetic Variability and Sensitivity of Pistia stratiotes Accesses to Glyphosate
}

\author{
CÍCERO, E.A.S. ${ }^{2}$, PITELLI, R.A. ${ }^{3}$, SENA, J.A.D. ${ }^{4}$ e FERRAUDO, A.S. ${ }^{5}$
}

\begin{abstract}
RESUMO - A alface-d'água (Pistia stratiotes) é uma das principais entre as macrófitas aquáticas que causam problemas em corpos hídricos no Brasil e são consideradas como plantas daninhas. O presente trabalho foi realizado com os objetivos de conhecer melhor a variabilidade genética dessa macrófita e relacionar essa variabilidade com a resposta à aplicação do herbicida glyphosate. Para isso, foram coletados indivíduos em 12 corpos hídricos em diferentes cidades do território nacional (Americana, Cambaratiba, Curitiba, Itapura, Jaboticabal, Lagoa Santa, Piraí, Rio Grande, Rubinéia, Salto Grande, Santa Gertrudes e Três Lagoas). Os acessos foram caracterizados pelo uso de marcadores RAPD (DNA Polimórfico Amplificado ao Acaso), que permitiram, com o auxílio de iniciadores aleatórios, a caracterização dos locos polimórficos identificados por uma matriz de ausência e presença de bandas. Utilizando essa matriz, a análise de agrupamento permitiu nítida classificação dos acessos em três grupos com diferenças genéticas entre eles. Um ensaio de controle químico, com plantas mantidas em vasos plásticos $(5 \mathrm{~L})$ e pulverizadas com o herbicida glyphosate nas concentrações de $0,0,0,6,1,2,1,8$ e 2,4 $\mathrm{kg} \mathrm{ha}^{-1}$, identificou, utilizando avaliações aos 7,14 e 21 dias após aplicação, que as duas maiores doses promoveram melhor efeito herbicida. Foi verificado também que os acessos de Curitiba e Cambaratiba apresentaram menor suscetibilidade ao herbicida glyphosate. Não houve correspondência entre a estrutura de grupos dos acessos pela análise multivariada de agrupamento com a técnica RAPD e a suscetibilidade da alface-d'água ao glyphosate.
\end{abstract}

Palavras-chave: macrófita aquática, RAPD, alface-d'água, diversidade.

ABSTRACT - Water lettuce (Pistia stratiotes) is one the most important macrophytes, classified as weed and causing serious problems in watercourses in Brazil. The aim of this research was to evaluate the genetic variability of water lettuce and its relationship with this plant's susceptibility to glyphosate. Plant samples were collected in 12 water bodies in different regions in Brazil (Americana-AMC, Cambaratiba-CBT, Curitiba-CRB, Itapura-ITP, Jaboticabal-JBT, Lagoa Santa-LST, Pirai-PRI, Rio Grande-RGD, Rubinéia-RBN, Salto Grande-SGD, Santa Gertrudes-SGT and Três Lagoas-TLG). The accesses were characterized by the use of RAPD markers (Random Amplified Polymorphic DNA), whose unspecific starters allowed the analysis of polymorphic loci, which evidenced the distribution of the accesses into two groups, with high genetic similarity inside the sub-groups, but with high genetic divergence between them. The use of the RAPD technique evidenced the existence of genetic differences between the accesses. Plants growing in plastic pots $(5 \mathrm{~L})$ were sprayed with glyphosate at the concentrations of $0.0,0.6,1.2,1.8,2.4 \mathrm{~kg} \mathrm{ha}$. Herbicide effects were evaluated on the $7^{\text {th }}, 14^{\text {th }}$, and $21^{\text {st }}$ days after application (DAA) with control note attributions (0\% without control and $100 \%$ leading to the complete death of the plants). No correspondence was observed between the structure of the access groups by the grouping multivaried analysis using the RAPD technique and water lettuce susceptibility to glyphosate.

Keywords: aquatic macrophytes, RAPD, water lettuce, diversity.

1 Recebido para publicação em 8.2.2007 e na forma revisada em 31.8.2007.

2 Pós-graduanda em Microbiologia Aplicada à Agropecuária da FCAV-UNESP, Jaboticabal-SP, <ciceroes@ fcav.unesp.br>; ${ }^{3}$ Prof. Titular, Dep. de Biologia Aplicada à Agropecuária - FCAV/UNESP, Via de Acesso Prof. Paulo Donato Castellane, s/n, 14884-900 Jaboticabal-SP, <pitelli@ fcav.unesp.br>; ${ }^{4}$ Prof ${ }^{a}$ Assistente, Doutora, Dep. de Biologia Aplicada à Agropecuária - FCAV/UNESP, Via de Acesso Prof. Paulo Donato Castellane, s/n, 14884-900 Jaboticabal-SP, <janete@ fcav.unesp.br>; ${ }^{5}$ Prof. Assistente, Doutor, Dep. de Ciências Exatas - FCAV/UNESP, Via de Acesso Prof. Paulo Donato Castellane, s/n, 14884-900 Jaboticabal-SP, <ferraudo@ fcav.unesp.br>. 


\section{INTRODUÇÃO}

As macrófitas aquáticas apresentam grande plasticidade fenotípica, o que as torna capazes de colonizar os ambientes com as mais diversas características físicas e químicas. Representadas por diferentes tipos biológicos, as plantas aquáticas, durante seu processo evolutivo, retornaram do ambiente terrestre para o ambiente aquático, mostrando marcada gradação nas adaptações associadas com a colonização deste último ambiente (Sculthorpe, 1967; Pierini \& Thomaz, 2004).

Dentre as mais importantes macrófitas aquáticas, destaca-se a alface-d'água (Pistia stratiotes). Nativa do continente sul-americano, essa planta rapidamente foi levada para vários locais do mundo, em decorrência do caráter ornamental de sua folhagem. Nos locais onde foi introduzida, essa macrófita causa inúmeros problemas os usos múltiplos dos corpos hídricos (Kissmann, 1997). Dentre os efeitos mais comumente citados em decorrência de densas e extensas colonizações de alface-d'água encontram-se: redução da biodiversidade (Cilliers et al., 1996; Winton \& Clayton, 1996), prejuízos aos esportes náuticos, entupimento de tubulações e canais de irrigação e, mais recentemente, prejuízos à produção de energia em usinas hidrelétricas (Mitchell et al., 1990; Itaipu Binacional, 1997; Thomaz \& Bini, 1999).

Considerando a importância das macrófitas aquáticas e de seus impactos sobre as comunidades aquáticas e atividades do homem, há um número relativamente pequeno de estudos publicados com essas plantas, especialmente em termos de controle químico, talvez pelo número limitado de herbicidas registrados para ambiente aquático. Dos mais de 200 diferentes herbicidas registrados (diferentes princípios ativos) nos Estados Unidos, apenas seis deles são registrados para uso aquático. Os herbicidas 2,4-D, diquat, complexos de cobre e endothal têm sido utilizados desde 1940-50; fluridone e glyphosate foram desenvolvidos em 1970; enquanto triclopyr e imazapyr ainda estão sendo avaliados para uso em ambientes aquáticos (Haller, 1998). Segundo Cardoso et al. (2003), por melhor atender ao binômio eficiência e custo, os herbicidas mais utilizados são 2,4-D, glyphosate e diquat. No Brasil, esses estudos são bastante escassos quando comparados aos de outros países, como EUA, Austrália e Nova Zelândia (Cardoso et al., 2003); portanto, o controle químico é um método promissor e se encontra em fase de regulamentação na legislação brasileira (Martins et al., 2005).

Segundo Thomaz (2002), o grande desafio consiste em empregar o manejo voltado para a manutenção da função ecológica das macrófitas aquáticas e não utilizá-lo buscando simplesmente a eliminação das populações. Tendo em vista o importante papel das macrófitas aquáticas, uma parcela de suas populações deve sempre ser mantida, a fim de preservar os "benefícios ecológicos" decorrentes de sua presença. Dessa forma, embora em algumas situações o manejo seja realmente necessário no sentido de reduzir as extensões e/ou as densidades das populações de macrófitas, ele também poderia ser utilizado para estimular a colonização e o incremento dessa vegetação. Para isso, o conhecimento básico das características das populações de macrófitas é fundamental, especialmente sua variabilidade genética e suas correlações com as variáveis ambientais ou de controle envolvidas nos sistemas de manejo empregados.

Os marcadores moleculares tipo RAPD são ferramentas importantes, pois oferecem subsidios para estimar a variabilidade genética dentro da espécie. Pesquisas sobre variabilidade genética com o uso de marcadores moleculares tipo RAPD têm sido amplamente utilizadas em plantas daninhas aquáticas, como Eichhornia crassipes (Cardoso et al., 2003), Egeria densa e Egeria najas(Martins et al., 2005) e P. stratiotes (Cardoso et al., 2005). Essa metodologia pode fornecer subsídios para avaliação da origem e dispersão de espécies nativas ou exóticas, além de servir como ponto de partida para estudos de manejo (Martins, 2003).

O presente trabalho teve por objetivos avaliar a variabilidade genética em plantas de alfaces-d'água provenientes de diferentes corpos hídricos localizados em cinco Estados brasileiros e verificar a existência de correspondência entre grupos de acessos formados pela técnica RAPD e grupos de acessos formados por avaliações da sensibilidade ao herbicida glyphosate. 


\section{MATERIAL E MÉTODOS}

Plantas de alface-d'água foram coletadas em oito incursões em corpos hídricos dos Estados de São Paulo (Americana, Cambaratiba, Itapura, Jaboticabal, Rio Grande, Rubinéia, Salto Grande e Santa Gertrudes), Paraná (Curitiba), Goiás (Lagoa Santa), Mato Grosso do Sul (Três Lagoas) e Rio de Janeiro (Piraî), perfazendo uma coleta total de 12 acessos. Todos os pontos foram georreferenciados por meio de um aparelho GPS Garmin 12S (Tabela 1). Após a coleta, as plantas foram transportadas para área experimental do Núcleo de Estudos e Pesquisas Ambientais em Matologia (Nepeam) da Faculdade de Ciências Agrárias e Veterinárias, UNESP, campus de Jaboticabal-SP.

Para extração do DNA genômico, foram utilizadas folhas jovens de alface-d'água de cada acesso, seguindo a metodologia descrita por Lodhi et al. (1994). Na análise das diversidades genéticas entre as plantas foi empregada a técnica RAPD, do protocolo original de Williams et al. (1990), utilizando 37 primers de seqüências arbitrárias de 10 bases, provenientes da coleção da University of British Columbia, Nucleic Acid Protein Service Unit (Canadá) e os produzidos pela Operon Technologies.

As reações de PCR foram amplificadas em um aparelho termociclador marca MJ Research,

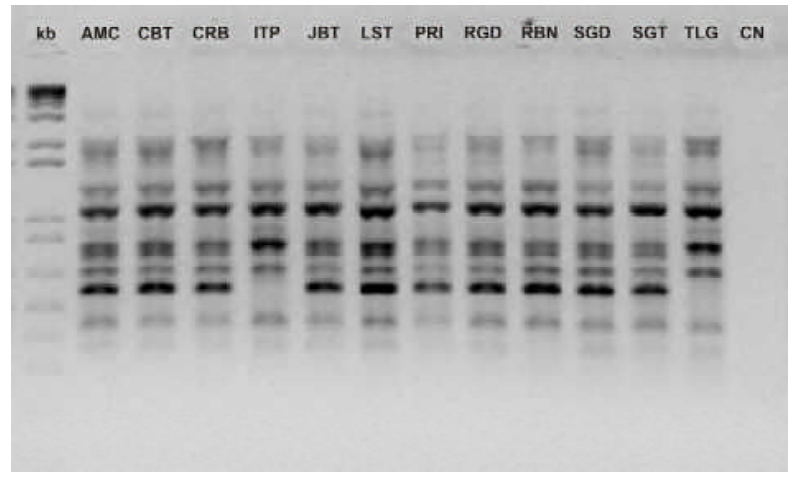

Figura 1 - Padrão de bandas polimórficas amplificadas por RAPD, com o primer OPAL10. Nota-se que os acessos ITP e TLG apresentam o mesmo perfil, diferindo dos demais acessos estudados. $1 \mathrm{~kb}$ - Marcador Molecular; AMC - Americana; CBT - Cambaratiba; CRB - Curitiba; ITP - Itapura; JBT -Jaboticabal; LST - Lagoa Santa; PRI - Piraí; RGD - Rio Grande; RBN - Rubinéia; SGD - Salto Grande; SGT - Santa Gertrudes; TLG - Três Lagoas; CN - Controle Negativo.
Inc., modelo (PTC-100 TM), equipado com circuito Hot Bonnet, perfazendo um ciclo de $92{ }^{\circ} \mathrm{C}$ ( $1 \mathrm{~min}), 35^{\circ} \mathrm{C}(1 \mathrm{~min}), 72{ }^{\circ} \mathrm{C}(2 \mathrm{~min})$, repetindose 42 vezes os passos 1,2 e 3 , e, finalmente, um ciclo de $72{ }^{\circ} \mathrm{C}$ (10 min), para completa extensão da fita de DNA. Após esse tempo, as amostras foram mantidas a $10{ }^{\circ} \mathrm{C}$ constantes, até o momento das análises.

As amostras amplificadas foram analisadas em gel de agarose $1,5 \%$, sob corrente elétrica de $110 \mathrm{v}$, por 90 minutos, utilizando o tampão de corrida TBE e $3 \mu \mathrm{L}$ de tampão de carregamento. Os fragmentos amplificados pela PCR e separados por eletroforese foram comparados com o DNA de tamanho molecular conhecido ("1 Kb Plus DNA Ladder"). Por meio da análise do bandeamento produzido por cada primer, foi conferido o parâmetro "um" para presença de banda e "zero" para ausência de banda (Figuras 1 e 2), permitindo a elaboração de uma matriz binária.

Para avaliar os efeitos das doses do glyphosate sobre cada acesso, foi instalado um ensaio fatorial, com delineamento inteiramente casualizado, nos quais constituíram variáveis os 12 acessos e cinco doses do herbicida glyphosate, formulação Rodeo $(0,0,0,6,1,2,1,8 \mathrm{e}$ $\left.2,4 \mathrm{~kg} \mathrm{ha}^{-1}\right)$. Três plantas de alface-d'água no estádio de 3-4 folhas foram cultivadas em vasos de polipropileno com capacidade para

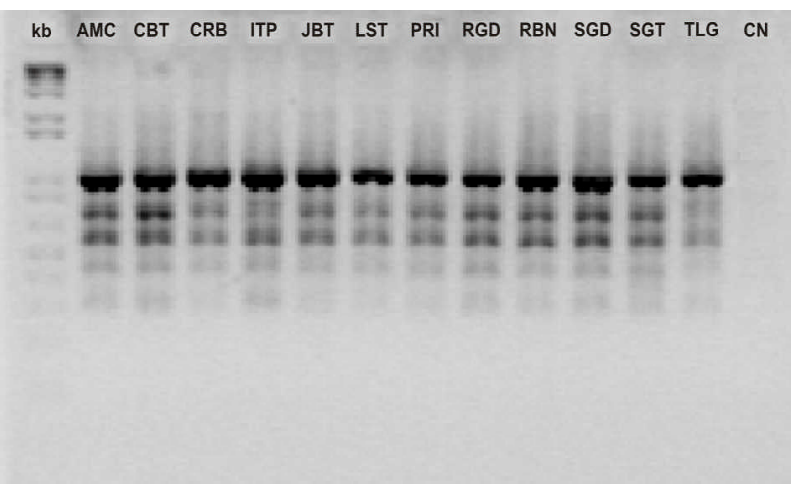

Figura 2 - Padrão de bandas monomórficas amplificadas por RAPD, com oprimer OPOX17, dos acessos estudados. 1 kb - Marcador Molecular; AMC - Americana; CBT Cambaratiba; CRB - Curitiba; ITP - Itapura; JBT Jaboticabal; LST - Lagoa Santa; PRI - Piraí; RGD - Rio Grande; RBN - Rubinéia; SGD - Salto Grande; SGT Santa Gertrudes; TLG - Três Lagoas; CN - Controle Negativo. 
$5 \mathrm{~L}$. Os vasos foram identificados e preenchidos com um litro de substrato na proporção 2:1:1 (terra:areia de rio:turfa), completado com água até $1 \mathrm{~cm}$ da borda. A aplicação foi realizada um mês após o plantio, quando as plantas apresentavam 5-7 folhas, utilizando um pulverizador costal pressurizado $\left(\mathrm{CO}_{2}\right)$ com barra munida de quatro pontas de pulverização com bicos de jato plano; a ponta utilizada foi XR 110.02, proporcionando uma vazão de $200 \mathrm{~L} \mathrm{ha}^{-1}$, a uma pressão de 40 psi.

As avaliações dos sintomas de fitointoxicação do glyphosate foram feitas aos $7,14 \mathrm{e}$ 21 dias após a aplicação (DAA), conforme uma escala percentual de notas de $0 \%$ (sem nenhum controle) a $100 \%$ (controle total das plantas), segundo recomendações da Sociedade Brasileira da Ciência das Plantas Daninhas (1995).

A análise de agrupamento foi utilizada para avaliar se a estrutura de grupos, contida nos acessos, formada pela técnica RAPD, bem como para as avaliações de sensibilidade ao herbicida glyphosate. O coeficiente de semelhança adotado foi a distância euclidiana, e a estratégia de agrupamento, o método de Ward (Hair et al., 2005). As matrizes utilizadas foram: matriz das notas dos acessos nas diferentes doses e matriz binária com a presença ou ausência de bandas pela técnica RAPD.

A análise de variância foi efetuada pelo teste $\mathrm{F}$, e as médias dos tratamentos, comparadas pelo teste $t$ a $5 \%$.

\section{RESULTADOS E DISCUSSÃO}

\section{Variabilidade Genética}

O emprego da técnica RAPD evidenciou a existência de diferenças genéticas entre os acessos de $P$. stratiotes. Dentre os 37 primers utilizados, 25 proporcionaram eficiência na amplificação das amostras, obtendo-se um total de 110 bandas polimórficas e 68 bandas monomórficas. Os padrões de bandas gerados pelas reações de RAPD foram nítidos e geraram bandas de média a boa intensidade. Assim, os iniciadores permitiram boa amplificação de todas as amostras e demonstraram a existência de variabilidade genética entre as populações dessa macrófita, pela produção de bandas polimórficas. Na Figura 1 estão representadas as bandas provenientes da amplificação dos acessos com o iniciador identificado por OPAL10, onde se observam regiões polimórficas, identificadas pela presença de bandas em algumas amostras em detrimento de outras.

Doze primers não amplificaram nenhuma das amostras, indicando que não havia uma região de homologia com tais primers, e, portanto, foram descartados da análise. A variabilidade genética em acessos de plantas daninhas foi observada por Vidal et al. $(2005,2006)$ em Bidens pilosa. Em macrófitas aquáticas também foi observada variabilidade genética em acessos de Pistia stratiotes e Eichhornia crassipes (Cardoso, 2003; Cardoso et al., 2005).

A ocorrência de uma porcentagem relativamente alta de bandas monomórficas era esperada, pelo fato de todos os acessos serem derivados da mesma espécie e apresentarem predominantemente reprodução vegetativa (Figura 2). Entretanto, Mori et al. (1999), estudando variabilidade genética em E. najas, puderam puderam constatar que a condição de reservatório possibilitou o represamento da variabilidade genética desta espécie. Ocorreu migração definida da variabilidade no ambiente, principalmente via propagação vegetativa, carregada pelo fluxo das águas. A alta densidade populacional desta macrófita ( $E$. najas) facilitou a propagação sexuada, o que promoveu aumento na variabilidade genética.

As Figuras 3 e 4 apresentam os filogramas gerados pelas análises de agrupamento. $\mathrm{Na}$ Figura 3 é apresentada a estrutura de grupos dos acessos formada pela técnica RAPD, enquanto na Figura 4 encontra-se a estrutura de grupos formada pelas avaliações do controle promovido pelo glyphosate aos 7 (a), 14 (b) e 21 (c) DAA. Observa-se que não foi possivel por RAPD, tampouco por avaliações, discriminar grupos de acessos suscetiveis e resistentes ao herbicida glyphosate.

Quando foi utilizada a técnica RAPD (Figura 3), o grupo A (Itapura - ITP e Três Lagoas TLG) ficou discriminado dos grupos B e C. Possivelmente, esses acessos podem ser resultados de uma eventual reprodução sexuada local, pois ambos foram coletados no mesmo reservatório (Jupiá). Esses resultados estão de acordo com os de Cardoso et al. (2005), que encontraram 


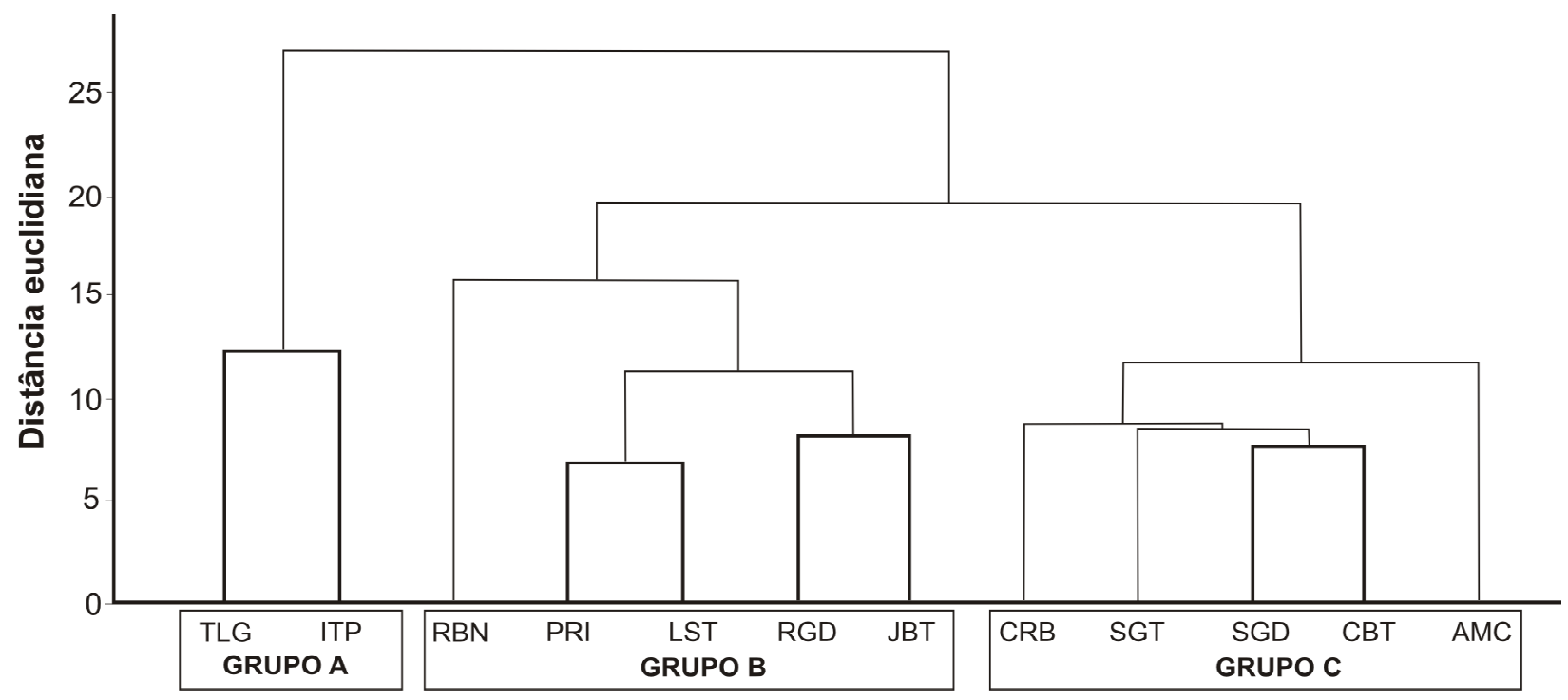

Figura 3 - Filograma dos 12 acessos de P. stratiotes, com base nos dados de 178 bandas obtidas de 25 primers de RAPD.

diferenças genéticas mais marcantes entre acessos coletados em reservatórios distantes. Esses autores também observaram maior distância genética das populações de $P$. statiotes coletadas em Jupiá, em relação às demais, e atribuíram isso ao fato de ser este reservatório um conversor de águas e possuir uma fonte mais complexa de material vegetal.

Quando se utilizou a matriz de avaliações (Figura 4a, b, c), as estruturas de grupos foram diferentes da estrutura obtida pela técnica RAPD (Figura 3), não permitindo classificação que discrimine em grupos tolerantes e, ou, suscetiveis ao herbicida glyphosate.

\section{Controle Químico}

Os resultados evidenciam interação entre a origem das plantas de $P$. stratiotes e as doses de glyphosate e serão discutidos com base nos desdobramentos das interações, aos 7, 14 e 21 dias (Tabela 2).

Os efeitos das diferentes doses do glyphosate, aos 7 DAA (Tabela 3), mostram que a dose de $0,6 \mathrm{~kg} \mathrm{ha}^{-1}$ apresentou maior eficácia nos acessos RGD (62,4\%), SGD (54,5\%) e TLG $(59,7 \%)$, quando comparados aos demais acessos, principalmente pelo acesso LST, que mostrou a pior taxa de controle $(23,4 \%)$. Com a dose de $1,2 \mathrm{~kg} \mathrm{ha}^{-1}$, o melhor controle foi registrado no acesso SGD $(73,5 \%)$, e o pior, no LST $(30,6 \%)$.
Com a dose de $1,8 \mathrm{~kg} \mathrm{ha}^{-1}$, o melhor controle foi verificado no acesso SGT $(82,3 \%)$, e o pior, nos acessos CRB (43,6\%) e AMC (49,4\%). Já na dose de $2,4 \mathrm{~kg} \mathrm{ha}^{-1}$, o melhor controle foi no acesso PRI (82,3\%), e o pior, no AMC (54,3\%).

Aos 14 DAA (Tabela 3), com a dose de $0,6 \mathrm{~kg} \mathrm{ha}^{-1}$, o melhor controle foi no acesso TLG $(84,2 \%)$, e o pior, no acesso LST $(35,8 \%)$. Com a dose de $1,2 \mathrm{~kg} \mathrm{ha}^{-1}$, o melhor controle foi nos acessos TLG $(88,0 \%)$, e SGD $(86,2 \%)$ e o pior, em LST $(45,2 \%)$, seguidos dos acessos AMC $(52,6 \%)$ e CRB $(56,4 \%)$. Na dose de $1,8 \mathrm{~kg} \mathrm{ha}^{-1}$, o melhor controle foi nos acessos ITP, PRI, RGD e SGT (90\%), e o pior, no acesso CRB $(61,4 \%)$. Na dose de 2,4 $\mathrm{kg} \mathrm{ha}^{-1}$, o melhor controle foi nos acessos JBT, RGD, RBN e TLG (90\%), e o pior, no acesso CRB (59,6\%).

Aos 21 DAA (Tabela 3), com a dose de $0,6 \mathrm{~kg} \mathrm{ha}^{-1}$, o melhor controle foi no acesso TLG $(90,0 \%)$, e o pior, no acesso LST $(42,7 \%)$. Na dose de $1,2 \mathrm{~kg} \mathrm{ha}^{-1}$, o melhor controle foi com os acessos TLG e SGD (90,0\%), e o pior, no acesso LST (53,7\%). Com a dose de 1,8 $\mathrm{kg} \mathrm{ha}^{-1}$, o melhor controle foi nos acessos ITP, LST, PRI, RBN, SGT e TLG (90,0\%), enquanto o pior controle foi no acesso CRB (73,0\%). Com a dose de $2,4 \mathrm{~kg} \mathrm{ha}^{-1}$, o melhor controle foi nos acessos AMC, JBT, LST, PRI, RBN e TLG (90\%), e o pior controle ocorreu no acesso CRB $(69,0 \%)$.

$\mathrm{Na}$ avaliação das doses, para cada acesso, aos 7, 14 e 21 DAA, observou-se que as duas 

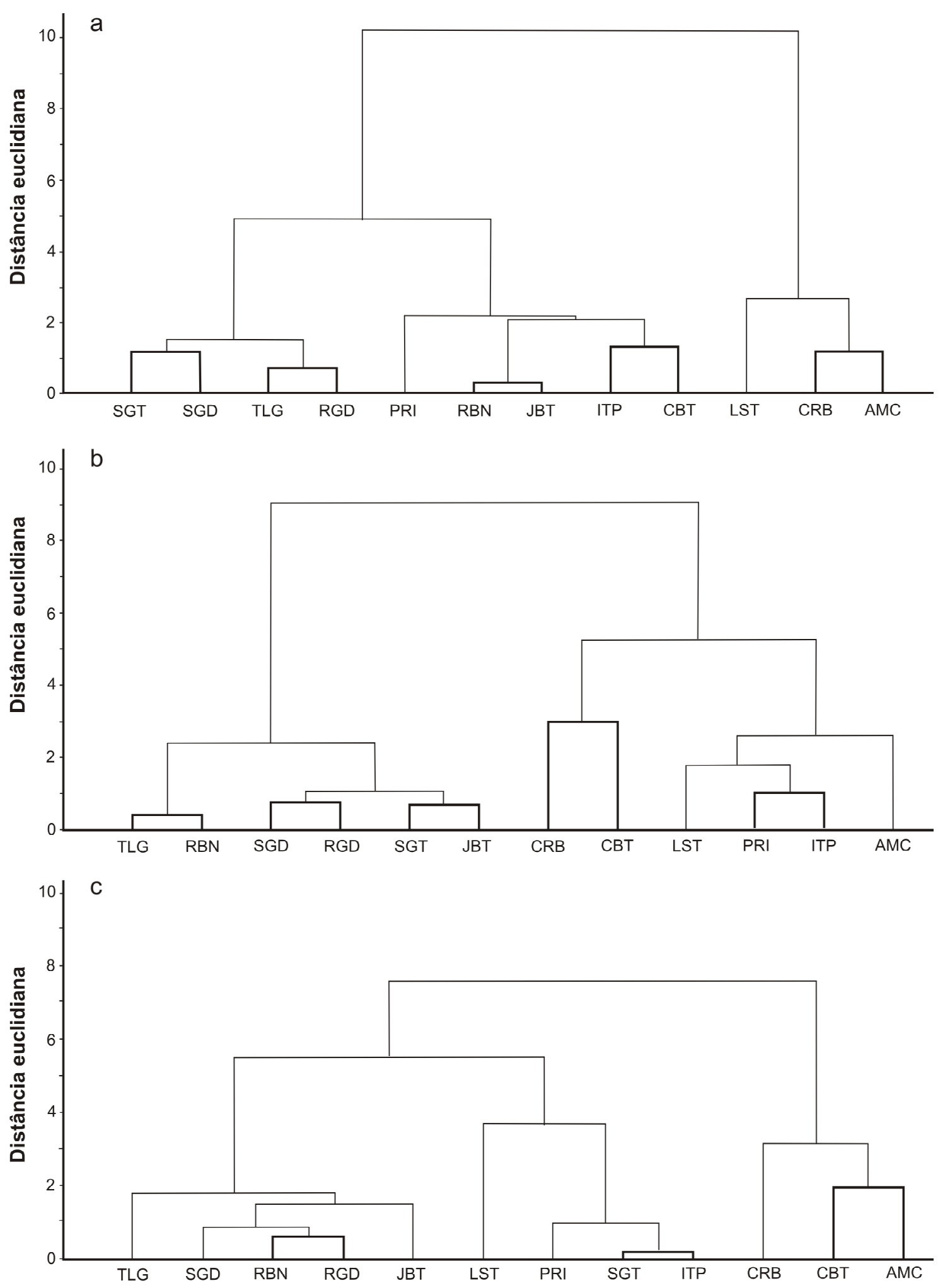

Figura 4 - Filogramas aos 7 (a), 14 (b) e 21 (c) DAA do herbicida glifosato nos 12 acessos, em 2003. 
Tabela 1 - Coordenadas geográficas dos locais de coleta, com os respectivos códigos dos 12 acessos de $P$. stratiotes presentes nos reservatórios

\begin{tabular}{|c|c|c|c|c|}
\hline Acesso & Estado & Código & Latitude & Longitude \\
\hline Americana & SP & AMC & $\mathrm{S} 22^{\circ} 44^{\prime} 20^{\prime \prime}$ & $\mathrm{W} 47^{\circ} 19^{\prime} 52^{\prime \prime}$ \\
\hline Cambaratiba & SP & CBT & S $20^{\circ} 06^{\prime} 68^{\prime \prime}$ & $\mathrm{W} 51^{\circ} 00^{\prime} 21^{\prime \prime}$ \\
\hline Curitiba & SP & CRB & $\mathrm{S} 25^{\circ} 25^{\prime} 40^{\prime \prime}$ & $\mathrm{W} 49^{\circ} 16^{\prime} 23^{\prime \prime}$ \\
\hline Itapura & SP & ITP & $\mathrm{S} 20^{\circ} 38^{\prime} 44^{\prime \prime}$ & W 51 $01^{\circ} 35^{\prime \prime}$ \\
\hline Jaboticabal & SP & JBT & $\mathrm{S} 21^{\circ} 15^{\prime} 20^{\prime \prime}$ & W 48 58' 90"' \\
\hline Lagoa Santa & GO & LST & $\mathrm{S} 19^{\circ} 11^{\prime} 38^{\prime \prime}$ & $\mathrm{W} 51^{\circ} 21^{\prime} 40^{\prime \prime}$ \\
\hline Piraí & $\mathrm{RJ}$ & PRI & $\mathrm{S} 22^{\circ} 41^{\prime} 02^{\prime \prime}$ & $\mathrm{W} 43^{\circ} 49^{\prime} 45^{\prime \prime}$ \\
\hline Rio Grande & SP & RGD & 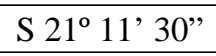 & W 48 $09^{\prime} 35^{\prime \prime}$ \\
\hline Rubinéia & SP & RBN & $\mathrm{S} 20^{\circ} 11^{\prime} 12^{\prime \prime}$ & $\mathrm{W} 51^{\circ} 00^{\prime} 49^{\prime \prime}$ \\
\hline Salto Grande & SP & SGD & $\mathrm{S} 22^{\circ} 53^{\prime} 41^{\prime \prime}$ & $\mathrm{W} 49^{\circ} 59^{\prime} 29^{\prime \prime}$ \\
\hline Santa Gertrudes & SP & SGT & $\mathrm{S} 22^{\circ} 28^{\prime} 35^{\prime \prime}$ & $\mathrm{W} 47^{\circ} 30^{\prime} 49^{\prime \prime}$ \\
\hline Três Lagoas & MS & TLG & $\mathrm{S} 20^{\circ} 38^{\prime} 42^{\prime \prime}$ & $\mathrm{W} 51^{\circ} 31^{\prime} 50^{\prime \prime}$ \\
\hline
\end{tabular}

Tabela 2 - Valores F obtidos na análise de variância dos dados, em porcentagem de controle, em vários acessos de P. stratiotes, aos 7, 14 e 21 dias após aplicação de diferentes doses de glifosato

\begin{tabular}{|l|c|c|c|}
\hline Fonte de variação & 7 dias & 14 dias & \multicolumn{1}{c|}{21 dias } \\
\hline $\mathrm{F}_{\text {Acesso (A) }}$ & $29,4^{* *}$ & $24,8^{* *}$ & $10,9 * *$ \\
\hline $\mathrm{F}_{\text {Dose (D) }}$ & $662,6^{* *}$ & $1159,9 * *$ & $894,5^{* *}$ \\
\hline $\mathrm{F}_{(\mathrm{A}) \mathrm{X}(\mathrm{D})}$ & $4,4^{* *}$ & $6,6^{* *}$ & $3,0 * *$ \\
\hline $\mathrm{CV}(\%)$ & 12,4 & 9,33 & 10,51 \\
\hline
\end{tabular}

maiores doses (1,8 e 2,4 $\left.\mathrm{kg} \mathrm{ha}^{-1}\right)$ apresentaram melhor resposta ao herbicida glyphosate (Tabela 3). As piores avaliações em todas as doses foram observadas nos acessos CRB e $\mathrm{CBT}$, o que pode ser indicativo de resistência ao herbicida glyphosate. Considerando que durante alguns anos este produto foi registrado para controle de macrófitas aquáticas, é possível que uma utilização mais intensiva desse herbicida no futuro possa promover seleção de acessos mais resistentes, embora não tenha sido encontrado registro bibliográfico da utilização deste herbicida nesses corpos hídricos no Brasil.

O emprego da técnica RAPD evidenciou a existência de diferenças genéticas entre os acessos de $P$. stratiotes, indicando variabilidade genética entre eles, sobretudo entre os acessos de Itapura (ITP) e Três Lagoas (TLG), discriminados num grupo isolado dos demais acessos, corroborando os estudos sobre caracterização genética em Egeria najas realizados por Mori et al. (1999). De acordo com esses autores, o reservatório tem possibilitado o represamento de variabilidade genética que tem migrado ao ambiente, principalmente via propagação vegetativa, carregada pelo fluxo das águas. No entanto, esta nova situação ambiental - de alta densidade populacional - facilitou o aumento da variabilidade genética entre as populações, ou, ainda, poderia estar associada uma eventual reprodução por sementes. Com essa nova situação ambiental, as espécies poderiam estar sendo auxiliadas por polinizadores e promovendo, assim, a diversidade genética.

A reprodução sexuada em $P$. stratiotes parece estar em processo de degeneração. No entanto, segundo Kissmann (1997), há eventual reprodução por sementes, formadas em quantidades significativas quando existem polinizadores adequados. Assim, alguns indivíduos decorrentes deste tipo de propagação podem ser bem sucedidos e formar novas populações, aumentando a variabilidade dentro da espécie, como observado nos acessos ITP e TLG, devido ao represamento da usina de Jupiá.

Os resultados obtidos permitiram concluir que a variabilidade genética das populações de $P$. stratiotes não tem correspondência com a resposta de tolerância ou sensibilidade ao glyphosate. 


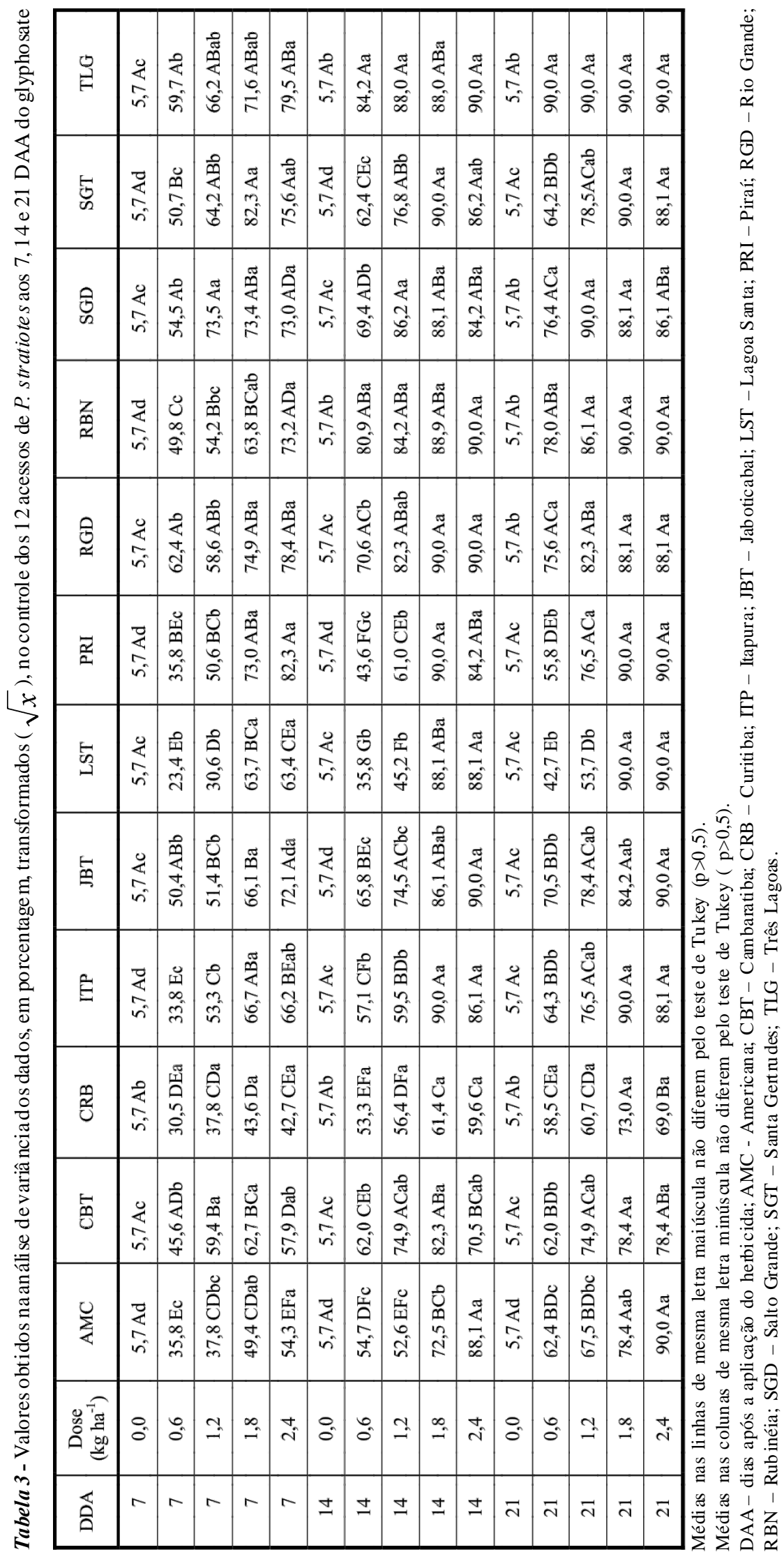




\section{LITERATURA CITADA}

CARDOSO, L. R.; MARTINS, D.; TERRA, M. A.

Sensibilidade a herbicidas de acessos de aguapé coletados em reservatórios do Estado de São Paulo. Planta Daninha, v. 21, p. 61-67, 2003. Edição Especial.

CARDOSO, L. R. et al. Variabilidade genética entre populações de Pistia stratiotes. Planta Daninha, v. 23, n. 2, p. 181-185, 2005.

CILLIERS, C. J.; ZELLER, D.; STRYDOM, G. Short - and log-ter control of water lettuce (Pistia stratiotes) on seasonal water bodies and on a river system in the Kruger National Park, South Africa. Hydrobiologia, v. 340, p. 173-179, 1996.

HALLER, W. T. Options for mechanical and chemical aquatic weed control. In: WORKSHOP CONTROLE DE PLANTAS AQUÁTICAS, 1998, Brasília. Resumos... Brasília: Instituto Brasileiro de Meio Ambiente e dos Recursos Naturais Renováveis, 1998. p. 46-53.

HAIR, J. F. et al. Análise multivariada de dados. 5.ed. Porto Alegre: 2005. 600 p.

ITAIPU BINACIONAL. Ocorrência de plantas aquáticas em reservatórios de usinas hidrelétricas. Foz do Iguaçu: 1997. 9 p. (Relatório).

KISSMANN, K. G. Plantas infestantes e nocivas. 2.ed. São Bernardo do Campo: BASF, 1997. 852 p.

LODHI, M. A.; GUANG-NIN, Y.; REISCH, B. I. A simple and efficient method for DNA extration from grapevine cultivars and Vitis sapequeis. Molec. Biol. Reporter, v. 12, p. 6-13, 1994.

MARTINS, D. et al. Caracterização genética de acessos de egéria (Egeria spp.) coletados no Estado de São Paulo. Planta Daninha, v, 21, p. 1-6, 2003. Edição Especial.

MARTINS, D. et al. Efeito de diferentes concentrações de aterbane na deposição de calda em plantas de Pistia

stratiotes. Planta Daninha, v. 23, n. 2, p. 343-348, 2005.
MITCHELL, D. S.; PIETERSE, A. H.; MURPHY, K. J. Aquatic plant problems and management in Africa. In: PIETERSE, A. H.; MURPHY, K. J. Aquatic Weeds. New York: Oxford Science Publications, 1990. p. 341-354.

MORI, E. S. et al. Caracterização genética de populações de Egeria najas presentes no reservatório de Jupiá e rios afluentes. Planta Daninha, v. 17, n. 2, p. 217-225, 1999.

NEI, M. Definition estimation of fixation indices.

Evolution, v. 40, p. 643-645, 1986.

PIERINI, S. A.; THOMAZ, S. M. Adaptações de plantas submersas à absorção do carbono inorgânico. Acta Bot.

Bras., v. 18, n. 3, p. 629-641, 2004.

SCULTHORPE, C. D. The biology of aquatic vascular plants. London: Belhaven Press, 1967.

SOCIEDADE BRASILEIRA DA CIÊNCIA DAS PLANTAS DANINHAS - SBCPD. Procedimentos para instalação, avaliação e análise de experimentos com herbicidas. Londrina: 1995.42 p.

THOMAZ, S. M.; BINI, L.M. Ecologia e manejo de macrófitas em reservatórios. Acta Limnol. Brás., v. 10, n. 1, p. 103-116, 1999.

THOMAZ, S. M. Fatores ecológicos associados à colonização e ao desenvolvimento de macrófitas aquáticas e desafios de manejo. Planta Daninha, v. 20, p. 21-33, 2002. Edição Especial.

VIDAL, R. A. et al. Similaridade genética entre acessos de Bidens pilosa resistentes aos inibidores da ALS. Planta Daninha, v. 23, n. 3, p. 551-556, 2005.

VIDAL, R. A. et al. Relação entre a distância geográfica e variabilidade genética de uma população de Bidens spp. com resistência aos herbicidas inibidores da ALS. Planta Daninha, v. 24, n. 1, p. 149-155, 2006.

WILLIANS, J. G. K.; KUBLEIK, A. R. K.; LIVAK, J. L. DNA polymorphisms amplified by arbitrary primers are useful as genetic markers. Nucleic Acids Res., v. 18, p. 6531-6535, 1990.

WINTON, M. D.; CLAYTON, J. S. The impact of invasive submerged weed species on seed banks in lake sediments. Aquatic. Bot., v. 53, p. 31-45, 1996. 